\title{
The Situation of Traffic Safety Issues in Vietnam: A Case Study of Ho Chi Minh City
}

\author{
Nguyen Xuan Truong* \\ University of Transport and Communications, Vietnam \\ *Corresponding Author \\ Nguyen Xuan Truong

\section{Article History} \\ Received: 13.06 .2020 \\ Accepted: 20.06.2020 \\ Published: 25.06.2020

\begin{abstract}
In Vietnam, traffic accidents are frankly recognized as a "catastrophe" because of the enormous consequences it has on their socio-economy, especially their irreparable mental injury. Prevention, avoidance and overcoming of traffic accidents are considered by the Party, the State, and the people to be a very important national task. This study focus on analyzing the situation of traffic violations of the people (the study of Ho Chi Minh City - the city with the highest traffic density and traffic violations in Vietnam,) causes of traffic violations, proposes solutions to limit traffic violations in Vietnam.
\end{abstract}

Keywords: traffic safety, traffic violation, Ho Chi Minh City, Vietnam.

\section{INTRODUCTION}

Since Vietnam's economy has changed from a centrally planned economy to a market economy (since 1986), the picture of Vietnam's economy has many bright spots, people's living standards have been improved step by step. Friends of regional and international countries wholeheartedly praised for the innovative achievements in the process of national construction. Although Vietnam's economic growth is quite high, it is accompanied by problems of traffic accidents and congestion, especially road traffic, the number of traffic incidents is constantly increasing in both scale and quantity. So many people often say that road traffic in Vietnam is like a balloon that can flatten one place after burst out, there are countless campaigns and instructions but only a short time, everything is back to the starting point [1].

Vietnam is the country with a stable political system in the region and in the world, it is a country with only one Political Party leading, terrorism is virtually absent. However, the number of people killed by traffic accidents is too many, on average 9.000 to 13.000 people die from traffic accidents each year (National Traffic Safety Committee, 2018). Economic losses are estimated at billions of dollars/year, equal to the value of rice exports (Vietnam has the secondlargest rice export volume in the world).

According to the National Traffic Safety Committee, in the first 5 months of 2019, there were 6.779 traffic accidents nationwide, killing 3,128 people and injuring 5.254 people. Compared to the same period in 2018, the number of traffic accidents decreased 711 cases (down 9.49\%), the number of deaths decreased by 348 people (decreased by $10 \%$ ), and the number of injured people decreased by 508 people (decreased by $8.82 \%$ ). Of which: Roads have occurred 6.695 cases, killing 3.077 people, injuring 5.229 people. In comparison with the same period last year, there were 704 cases decreased $(9.51 \%$ ), decreased 338 deaths (decreased 9.9\%), 521 injured people (decreased 9.06). Railway occurred 55 cases, killing 35 people and injuring 24 people. Compared with the same period last year, there were 3 cases increased (5.77\%), down 8 people (down 8.6\%), and 12 people injured (up 100\%) [2].

Waterway occurred 24 cases, killing 13 people and injuring 1 person. Compared to the same period last year, down 9 cases (down 27.27\%), down 4 deaths (down 23.53\%), the number of injured people increased by one person. The maritime incident occurred five cases, killing three people, no one was injured. Compared with the same period last year,

Copyright @ 2020: This is an open-access article distributed under the terms of the Creative Commons Attribution license which permits unrestricted use, distribution, and reproduction in any medium for non commercial use (NonCommercial, or CC-BY-NC) provided the original author and source are credited. 
there was a decrease of 1 case (down 16.67\%), an increase of two deaths and disappearance (200\%), the number of injured people did not change (Table-1) [2].

Table-1: Traffic accident for 3 years $(2017$ - 2019)

\begin{tabular}{|l|l|l|l|l|l|}
\hline Mumerical order & Content & $\mathbf{2 0 1 7}$ & $\mathbf{2 0 1 8}$ & $\mathbf{2 0 1 9}$ & Compare \\
\hline 1 & Number of accidents & $>20.000$ & $>18.700$ & $>18.600$ & Reduction \\
\hline 2 & Number of deaths & $>8.000$ & $>8.200$ & $>8.100$ & Reduction \\
\hline 3 & Number of injured & $>17.000$ & $>14.800$ & $>14.600$ & Reduction \\
\hline
\end{tabular}

Source: National Traffic Safety Committee

Also according to the National Traffic Safety Committee, Traffic accidents in May and 5 months of 2019 continued to reduce all 3 criteria in terms of cases, deaths and injuries compared to the same period in 2018; the basic traffic situation is guaranteed and smooth. However, in order to occur some particularly serious traffic accidents, which are alarming in the public opinion, it is alarming that the situation of drug use is a violation of the concentration of the driver of a vehicle causing a traffic accident special serious.

Looking at the number of deaths and economic losses, the waste and grief show the fate of the unfortunate people who have died due to their carelessness, other causes, or indifference of social management apparatus at all levels. What causes big and not worthy losses from traffic accidents? In addition to the above, non-compliance and lack of understanding of road traffic law are also one of the main causes of many serious traffic accidents causing great loss of lives and wealth, causing serious consequences for the development of the country.

\section{RESEARCH METHODS}

- $\quad$ Studying legal documents and regulations in the field of road traffic.

- Research using methods: the survey by questionnaire (number of votes issued and collected is 1,000 votes).

- Direct interviews with road users in some major cities of Vietnam.

- Due to the difficulty of distance, the author only focuses on research at Ho Chi Minh City

- The author directly observe and record (documents and images) the situation of road traffic participation at Ho Chi Minh City.

\section{Overview of the Traffic Situation in Ho Chi Minh City}

Assessing the situation of traffic order and safety of Ho Chi Minh City in 2019, the representative of the City Traffic Safety Committee said, compared to 2018, all three sides are the number of accidents, the number of deaths, and the number of people injuries are reduced. Despite the reduction in all 3 sides, there are still 3 localities where the situation of deaths increased from 10 to 44\%: District 9, Binh Thanh District, and Can Gio District. In particular, there was no traffic congestion in the city for over 30 minutes.

However, this situation is still complicated, partly because the number of personal vehicles continues to increase sharply. On average, there are 168 new cars and 868 motorbikes registered each day.

Another pressure that Ho Chi Minh City faces is ensuring roadside order. In nearly 200 routes, up to 29 routes are assessed as complex, 120 routes are evaluated as having changed [3].

In recent years, although the number of deaths due to traffic accidents and the number of traffic congestion in the city has decreased, there is still the potential for increased if the functional forces do not have a concentration with specific solutions physical and drastic.

Currently, the city's transport infrastructure continues to be affected by the increasing number of private cars; the situation of the sidewalks and sidewalks was reclaimed to be a place of business and trading; in many places, roads are not yet open and summer is not clear; Awareness of law observance of a part of people is limited.

According to the Department of Transport of Ho Chi Minh City, the city currently has nearly 3,800 roads with a total length of about $3,500 \mathrm{~km}$, the density of roads compared to the total area of the city is only $1.44 \mathrm{~km} / \mathrm{km} 2$ and reaching $1.56 \mathrm{~km} / \mathrm{km} 2$ (statistics in 2018) [3].

According to the standards of advanced countries, to meet the demand for smooth traffic, the road area density compared to the common area must reach $10-20 \%$. The above situation proves that the existing traffic system is overloaded, incapable of meeting regional traffic requirements, and circulating at rush hours. To overcome this situation, the city has a plan for transportation development up to 2020 and a vision after 2025 to complete and modernize transport 
infrastructure. However, capital constraints are the main obstacle in implementing the implementation plan of transport planning.

In addition to the causes of population increase and the increase in the means of transport, the awareness of compliance with traffic laws is still poor, so it has greatly affected the traffic situation and caused congestion blockage, slow down circulation time. Although the rules and laws to ensure road safety in Vietnam are relatively adequate, the implementation of the regulations has not been strictly followed by people [4]. People in traffic still tend not to give way when traveling, the situation of encroaching on the road, passing a red light, entering a forbidden road, etc is an image that often happens.

Currently, a number of projects that have to dig roads for the construction of urban technical infrastructure such as the installation of water supply pipes, electric cables, telephone cables, etc are being implemented on many main roads, narrowing the area. The area of roads for the city is already in shortage and significantly affects the movement of people, making traffic congestion more and more complicated.

The Department of Transport of Ho Chi Minh City assessed that traffic congestion increased, leading to an increase in air pollution, affecting the investment environment, and hindering the development of the city. In the current complicated traffic situation in the city, the management of urban traffic is still inadequate and has not completely solved the frequent traffic congestion in the city. The current traffic management model does not apply scientific methods, such as computer simulations of existing databases, to serve the planning and design of traffic engineering measures; Traffic infrastructure has not yet been built, advanced and modern technologies have not been applied in traffic management.

In 2020 is the year that Ho Chi Minh City implements the theme "Drinking without driving". In addition to propaganda, the city will implement a pilot project to apply science and technology to the process of sanctioning administrative violations in the transport sector [3].

\section{The Situation of Traffic Accidents in Ho Chi Minh City}

Many social researchers and public opinion have identified that traffic accidents in some countries, including Vietnam, are more catastrophic than in modern wars if compared with numbers. Casualties, socio-economic damage, and mental suffering for those who stay. According to statistics, on average, in Vietnam, about 8,000 people died, 15,000 were injured in traffic; the economic damage is estimated at the US \$ 5-12 billion and the mental damage is immense.

With the strong participation of the entire political system and the increased public awareness of traffic, the situation of traffic accidents is on the rise. According to the report of the National Traffic Safety Committee, in the first 6 months of 2019, traffic accidents decreased by all three criteria: A total of 8,385 traffic accidents (decreased by more than $7 \%$ ), resulting in 3,810 deaths. people (down more than 7.5\%), injured 6,358 people (down more than 9.6\%); In the whole country, there are 47 provinces and cities reducing the number of traffic accident deaths compared to the same period in 2018 [2]. This is considered to be the deepest reduction in many years. However, in modern society, the above figures are difficult to accept, as every day of the people in traffic in Vietnam will have about 20 people who will never return home [2].

There are many different studies, from both domestic and foreign experts, deciphering the causes of traffic accidents in Vietnam. Basically, it can be divided into groups of causes [5]:

Due to the awareness, responsibility, and culture of a large number of people involved in traffic are not good.

According to reports, the leading cause of traffic accidents, especially fatal tragedies, is caused by road users using alcohol and beer. In fact, there have been countless adversities, piling up more tragedy when happy days became sad days and sad days became sadder because after the "funerals, filial piety, joy" many people use alcohol when participating in traffic and becoming a victim or a person causing traffic accidents; In the common joyful days, the great celebration of the country, the number of cases, the number of people killed by traffic accidents all skyrocketed, many fates were no longer able to join with the joy of the whole country because of "missed" too cups or victims of alcohol users while in traffic, etc.

The traffic culture of many Vietnamese people is still a sad and even embarrassing thing. Anytime, anywhere, especially in big cities, can witness traffic safety violations, potentially causing traffic accidents, such as speeding, reckless overtaking, and disobedience operating traffic signals, not wearing helmets, carrying overloads, encroaching on lanes, wrong lanes, etc. At the peak time of traffic, traffic jams are chaotic and chaotic. At rush hours, at night, the amount of cars is low, again, the situation of speeding, overtaking, etc. Traffic Safety Law is often violated, both due to intentional violations or ignorance, but not few people considered it normal, even a way of "expressing themselves". As a result, breaking a traffic law to a traffic accident is just an instant. 
Due to poor traffic management of state agencies:

Reports of the traffic safety management levels also frankly admitted, the shortcomings of the traffic accident situation are due to the state management in directing and administering the implementation of security solutions traffic order and safety are not regular, continuous, and strong. Shown through some of the following:

The management of transportation activities is still inadequate. There are still many places in the training and testing of driving licenses and vehicle registration, sometimes not seriously implemented, leading to the situation that many vehicle owners may not be able to control and understand well enough on traffic safety regulations; Many vehicles participating in traffic do not guarantee the quality, safety, etc [3]. These things pose a potential risk of traffic safety at any time. The capacity and quality of the state management of traffic safety, transport business, vehicle technical management, protection of transport infrastructure are not good. From a macro perspective, there is no good forecast and strategy, planning for development with a long-term vision in a scientific and efficient way. In the aspect of regular management, there are still some shortcomings, such as the division and assignment between the authorities about ensuring order and traffic safety are not reasonable, lack of close coordination among branches and levels; inspection, examination and handling of traffic violations are still limited, concentrated in a number of areas, on key routes, during peak periods, overloaded vehicles still occur, etc [6]. Law enforcement is not seriously leading to a lack of deterrence, inefficiency. Meanwhile, negative phenomena in the performance of public duties still exist, manifesting as a part of officials, civil servants, and public employees also show signs of avoiding, being irresponsible, accepting bribes, doing contrary to regulations in dealing with traffic violations, etc. These things make the perception and culture of a part of people in traffic worse, and also cause the community and society to not really care about traffic problems. The current.

Due to transport infrastructure, transport facilities are still weak and outdated:

Currently, due to many different reasons, such as being used for many years, a huge amount of traffic is overloaded, the quality of construction and repair works is low and inadequate, due to inspiration. suffer from natural disasters and also the accidental or intentional destruction of some people when using sidewalks, even roadbeds, for business, trading, daily activities, etc., so the quality of several transport infrastructure works being There is a serious deterioration, often the situation of cartilage subsidence, landslides, flaking, "potholes, elephant holes" on the road, especially in places with large numbers of vehicles [3]. The safety of many vehicles participating in traffic is low. Can see daily countless motorbikes, old cars, other outdated vehicles; At the same time, keeping traffic safety for public equipment such as trains and buses is also carried out with poor and backward facilities. Those are also potential reasons for a traffic accident:

The entry of the entire political system is not yet strong:

Effective prevention and avoidance of traffic accidents require the participation of the entire political system, but this has not been strongly implemented. That leads to not mobilizing the power of the whole community to create a strong public opinion enough to create pressure and awareness forcing people to join the traffic and functional forces to promote their full potential knowledge and capacity to minimize unnecessary risks and traffic accidents.

\section{PROPOSING SOME SOLUTIONS}

Firstly, it is necessary to strengthen the leadership of the committees, authorities, and functional agencies in ensuring traffic safety. Speed up the effective implementation of Directive No. 18-CT/TW, dated September 4, 2012, of the 11th Central Party Central Committee Secretariat, on "Strengthening the Party's leadership in order to ensure order. road and railway safety, inland waterways and overcoming traffic congestion"; Resolution No. 88/2011/NQ-CP, dated August 24, 2011, of the Government on "Strengthening the implementation of key solutions to ensure traffic order and safety"; "National strategy for ensuring road traffic order and safety until 2020 with a vision to 2030" and directives, policies, and regulations on ensuring traffic safety. In this solution, it is necessary to emphasize the role of the head unit, local.

Local authorities and functional forces at all levels need to improve the efficiency and responsibility of traffic safety management, leadership, management of infrastructure planning and construction, and effective traffic development. As a result, it is necessary to strictly handle organizations and individuals that do not comply with the regulations on traffic safety; strengthen the application of science and technology to the management of vehicles.

Secondly, promote management and law enforcement to ensure traffic order and safety. Vietnam is promoting the building of a rule-based supremacy society in the construction of a socialist rule-of-law state, and the transport sector needs to be drastically implemented because there is a "disaster" happening here traffic accidents. It can be seen that, when and where, the traffic law enforcement and enforcement are carried out regularly and in accordance with the regulations, traffic order and safety are ensured, traffic accidents are ensured minimize and vice versa. Strong law enforcement not only helps detect and prevent in time but also has a great effect in deterring, setting an example, creating awareness, habits, and proper behaviors of people when participating traffic. In particular, in this work, it is necessary to 
strengthen inspection, control, and strictly deal with the violations of official duty, such as covering up, not strictly handling violations, receiving foreign exchange exposing, intentionally falsifying violations, etc.

Thirdly, focusing on mobilizing resources to build and develop modern and synchronous transport technical infrastructure, creating favorable conditions when participating in traffic. The committees, authorities, and functional sectors should continue to implement and implement effectively, on schedule, to ensure the quality of transport technical infrastructure works. In the immediate future, it is necessary to prioritize investment in traffic technical infrastructure works in roads where traffic flows are crowded, arterial roads, places where congestion and traffic accidents are frequently occurring informed.

Fourthly, focus on well implementing the propagation, dissemination, and education of laws on traffic order and safety, helping cadres, party members and people to be aware of the right behavior in participating in the delivery information, preventing traffic accident hazards. Propaganda must be synchronized, scientific, and comprehensive to achieve the highest efficiency. The motto is to ensure the "easy to understand, easy to remember, easy to follow", creating trust and consensus among the people. Ensuring the entry of the whole political system to create a movement of the entire population to exercise traffic safety and traffic participation culture.

Fifthly, promoting education, training, and fostering of participants in traffic. For people involved in traffic, it is the process from training conditions to traffic in a true and quality assurance manner; at the same time, it is always updated with new information in traffic. For the functional forces and the relevant branches of the transport sector are the requirements for training and retraining of civil service ethics as well as the qualifications and skills to serve the work with increasingly higher requirements for quality, expressed through the quality of the project, the ability to control the situation and traffic situation in accordance with the principle of superiority to the law, wholeheartedly, wholeheartedly serving the Fatherland, serving the people.

\section{CONCLUSION}

In order to minimize traffic accidents, first of all it is necessary to raise the awareness and awareness of compliance with the law on traffic order and safety of the people. At the same time warn of the risk of traffic accidents. In addition, it is necessary to create the best conditions for traffic infrastructure to ensure traffic safety by building more overpasses and tunnels for pedestrians, giving adequate road sections for pedestrians. Along with that, the organization mobilized the drivers of road motor vehicles to consciously proactively give way to pedestrians when crossing the road, avoiding recklessness, not drinking beer, alcohol when driving, etc.

Over the years, with the efforts of departments and agencies, the observance and understanding of regulations of transport vehicles owners in the Vietnam have improved. But with the above-mentioned situation, along with the rapid increase of transport vehicles when the vehicles owners have not certain knowledge when participating in transport in this field, it may cause catastrophic. Under these circumstances, propaganda and education for transport vehicles owners to understand their responsibilities is an important thing and needs to be done immediately.

Each of us to implement traffic safety, we need to establish ourselves a sense of responsibility for observing the rules when participating in traffic. Rules are set not just for compliance but for certain standards to protect our safety so please obey it for our own safety, not to deal with or to oppose it. Things like not passing a red light, speeding up, not drinking alcohol when in traffic, etc. should be strictly observed to create the foundation for a safe civilized society.

\section{REFERENCES}

1. Huy, N. Q. (2007). Implementing laws in the field of ensuring traffic order and safety (through the fact of Thai Nguyen province). Master thesis in Law, Faculty of Law - Hanoi National University.

2. National Traffic Safety Committee. (2017). On urgent measures to reduce traffic accidents at railroad crossings. Hanoi.

3. Department of Transportation Ho Chi Minh City. (2019). Report on traffic order and safety for 3 years (2017 2019).

4. Binh, N. V. (2017). Some experience in orderly restoration of passenger transport business by auto in Thanh Hoa. Journal of People's Public Security. No 8.

5. Phuong. P. (2019). Explanation on the situation of violations of traffic safety laws. Received from: https://hanoimoi.com.vn/tin-tuc/giao-thong/928569/giai-trinh-ve-tinh-hinh-vi-pham-phap-luat-an-toan-giao-thong. Read July 25, 2019

6. Vietnam Road Administration - Police Department of Administration and Social Order. (2016). Coordination Regulation on ensuring traffic order and safety corridor, protecting traffic works and road safety corridor Ministry. Hanoi. 